\title{
Lecturas de Spinoza: hacia una torsión materialista de las prácticas jurídicas
}

Spinoza readings: towards a materialistic twist of legal practices

Leituras de Spinoza: Rumo a uma torção materialista das práticas jurídicas

Lectures de Spinoza: vers une torsion matérialiste des pratiques juridiques

SPINOZA (斯宾诺莎) 的读物: 朝着法律实践的实质性转变

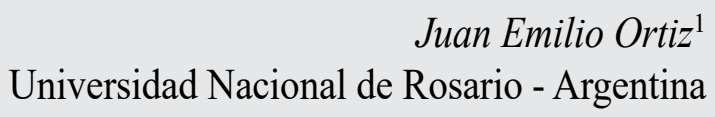

Revista Derechos en Acción ISSN 2525-1678/ e-ISSN 2525-1686

Año 5/No 16 Invierno 2020 (21 junio a 20 septiembre), 126-165

DOl: https://doi.org/10.24215/25251678e417

Recibido: $13 / 07 / 2020$

Aprobado: 14/08/2020

Resumen: El presente escrito indagará en algunas lecturas contemporáneas de Spinoza con una finalidad específica: pensar una torsión materialista para reflexionar sobre el Derecho con el fin de conectar al dispositivo con su dimensión real. El objetivo será cuestionar la fundamentación idealista de las prácticas jurídicas mostrando el anclaje de las instituciones en el movimiento afectivo de los individuos y las sociedades. De esta manera, será posible explorar una fundamentación

1 Profesor y Licenciado en Filosofía egresado de la Universidad Nacional de Rosario (UNR), Argentina. Estudiante del Doctorado en Humanidades y Artes en dicha Institución. Docente Adscripto y Auxiliar de Investigación en la cátedra Teoría Sociológica dictada en la Facultad de Humanidades y Artes (UNR); Empleado Administrativo del Poder Judicial, Ministerio Público de la Provincia de Buenos Aires, Argentina. juane_ortiz@hotmail.com. (ORCID: https:// orcid.org/0000-0002-8427-0774). 
del Derecho que no lo reduce a ser un mero instrumento de dominación, sino una herramienta democrática cuya potencia es imprescindible para generar transformaciones necesarias.

Palabras clave: Spinoza, Materialismo, Idealismo, Derecho, Ficción Jurídica, Afectos, Pasiones.

Abstract: The present writing will investigate some contemporary Spinoza readings with a specific purpose: to think of a materialist twist to reflect on the law in order to connect the device with its real dimension. The objective will be to question the idealistic foundation of legal practices showing the anchoring of institutions in the affective movement of individuals and societies. In this way, it will be possible to explore a foundation of law that does not reduce it to being a mere instrument of domination, but a democratic tool which power is essential to generate necessary transformations.

Keywords: Spinoza, Materialism, Idealism, Law, Legal Fiction, Affections, Passions.

Resumo: 0 presente trabalho investigará algumas leituras contemporâneas de Spinoza com um objetivo específico: pensar uma torção materialista para refletir sobre o direito com a fim de conectar o dispositivo com sua dimensão real. 0 objetivo será questionar o fundamento idealista das práticas jurídicas mostrando a ancoragem das instituições no movimento afetivo dos indivíduos e as sociedades. Dessa maneira, será possível explorar uma fundamentaçao do Direito que não o reduza a um mero instrumento de dominação, mas um instrumento democrático cuja potência é essencial para gerar transformações necessárias.

Palavras-chave: Spinoza, Materialismo, Idealismo, Direito, Ficção Jurídica, Afecções, Paixões.

Résumé: Cet essai explorera certaines lectures contemporaines de Spinoza avec un but précis: penser à une torsion matérialiste pour réfléchir sur la Loi afin de relier le dispositif à sa dimension réelle. L'objectif sera de remettre en question le fondement idéaliste des pratiques juridiques montrant l'ancrage des institutions dans le mouvement affectif des individus et des sociétés. De cette manière, il sera possible d'explorer un fondement du Droit qui ne le réduit pas à un simple instrument de domination, mais plutôt à un outil démocratique dont la puissance est essentielle pour générer les transformations nécessaires. 
Mot-clés: Spinoza, matérialisme, idéalisme, droit, fiction juridique, affections, passions.

摘要: 本书将研究 Spinoza (斯宾诺莎) 的一些当代读物, 其目的是 特定的: 思考一种物质主义的转折, 以反思法律, 以便将设备与实际 尺寸联系起来. 目的将是质疑法律实践的理想主义基础, 该理论表 明制度在个人和社会的情感运动中的根基. 这样, 将有可能探索法 律的基础，该基础不会将其缩减为仅仅是统治的工具，而是一种民 主工具, 其力量对于产生必要的转变至关重要.

关键字: Spinoza (斯宾诺莎), 唯物主义, 唯心主义, 法律, 法律小说, 感情, 激情

\section{Introducción}

Este escrito está motivado por la convicción de que la teoría y la praxis cotidiana del derecho necesitan vincularse adecuadamente con un ejercicio efectivo y serio de crítica filosófica. Muchos problemas actuales requieren de un conjunto de prácticas jurídicas que sean capaces de defender derechos humanos básicos ante el avance de formas de dominación cuya dinámica se ha vuelto imperceptible. Nuestro país ha experimentado recientemente los riesgos de la acumulación de capital financiero conjugado con el despliegue de políticas neoliberales. Su combinación explosiva se presenta como una amenaza permanente para derechos humanos básicos como la vida, la salud, la educación pública, la vivienda y el ambiente. Creo que estas cuestiones son potenciadas por algunas ficciones jurídicas que anidan en la fundamentación misma de nuestras instituciones y animan este tipo de lógicas de dominación con sus identidades correlativas.

Estas ficciones se presentan como cierres ideales que condicionan tanto el contenido de los derechos como las identidades a las que se aplican. En otras palabras, actúan en torno a algún principio de síntesis de carácter trascendente, empírico o incluso dialéctico. El problema con este tipo de fundamento apriorístico deviene cuando se pierde de vista su contenido 
ideológico y sedimentado por el ejercicio de las prácticas de gobierno. El dispositivo pierde así su dimensión real, se convierte en una finalidad en sí misma, desconociendo personas y procesos reales. En esta dinámica, diversos aspectos de la realidad se vuelven ilegales dependiendo del criterio de aquellos que manejan el aparato legal. Por esta razón, estudios ya clásicos como los de Michel Foucault, Gilles Deleuze, Giorgio Agamben enfatizan el papel del Derecho en la reproducción de identidades funcionales a diversas formas de dominación.

En consonancia con esas ideas, creo que es una tarea urgente desarticular cierto grado de idealismo que aún se cierne sobre la institución jurídica con el fin de pensar más rigurosamente su contacto con la dimensión real (óntica). Para ello, el presente escrito indagará en algunas lecturas contemporáneas del filósofo Baruch Spinoza (1632-1677) con una finalidad específica: Pensar una torsión materialista para abordar el Derecho. El objetivo será mostrar que la institución jurídica tiene un anclaje en el movimiento afectivo de los individuos y las sociedades. De esta manera, será posible explorar una fundamentación del Derecho que no lo reduce a ser un mero instrumento de dominación, sino una herramienta democrática cuya potencia es imprescindible para generar transformaciones necesarias.

\section{La recuperación del materialismo de Spinoza en el siglo $X X$}

Ahora bien, es sabido que la principal característica de la filosofía de Spinoza radica en su rechazo hacia las fundamentaciones trascendentes originadas en la imaginación. En el Tratado Político su método de inmanencia se aplica a reflexionar acerca de los fenómenos políticos produciendo una inversión significativa que sigue una línea ya abierta por Maquiavelo. ${ }^{2}$ Allí,

\footnotetext{
2 La innovación radical del pensador del florentino fue realzar la singularidad de lo político como un ámbito autónomo e irreductible a los principios que rigen la moral y la religión. Este método, supone un principio de acción sumamente realista que ayuda a repensar la función de las síntesis ideales. En este movimiento de desmontaje de ideas ilusorias Maquiavelo advirtió
} 
Spinoza sugiere que la dinámica política debe concebirse como una ciencia de los afectos y las pasiones dejando de lado los supuestos ilusorios acerca de aquello que las personas deberían ser. Desde el inicio del texto, Spinoza sugiere que los filósofos han interpretado como vicios un conjunto de comportamientos que son constitutivos de nuestra naturaleza. Siguiendo esta lógica, en el primer capítulo de sus Tratado político afirma:

Traté por todos los medios de no ridiculizar las acciones de los hombres, de no llorarlas, de no detestarlas, y adquirir en cambio de ellas un conocimiento exacto. He considerado asimismo los afectos humanos: el amor, el odio, la cólera, la envidia, la soberanía la piedad y los restantes movimientos del alma, no como vicios sino como propiedades de la naturaleza humana; modos de ser que les pertenecen, lo mismo que pertenecen a la naturaleza del aire, el calor, el frío, la tempestad, el trueno y todos los meteoros. (Spinoza, 2014: 30).

Siguiendo esta lógica, el pensador de Ámsterdam promueve el reemplazo de una moral idealista por un reconocimiento de las relaciones efectivas, pasionales, y conflictivas que articulan los procesos institucionales. A pesar del carácter aparentemente crudo de esta afirmación, la inversión sugerida por el filósofo en ningún momento promueve el caos y el sinsentido. Como analizaré más adelante, la innovación spinozaiana consiste en proponer una acción ética y racional capaz de conjugarse con el reconocimiento de la contingencia de las empresas humanas.

De acuerdo con lo anterior, es posible afirmar que Spinoza y Maquiavelo sientan las bases de un método radicalmente

\footnotetext{
ya en su tiempo el componente pasional que subyace a la cualquier acción política. Son las pasiones las que mueven los resortes en la vida de los hombres, constituyendo un horizonte de generalidad en el cual se dibujan de manera singular las instituciones que rigen una sociedad. En consecuencia, si alguien desea gobernar no es prudente que lo haga a partir de las ideas anquilosadas de la moral propia de tiempos pasados, sino reconociendo la dinámica del deseo inherente a la vida de los hombres. Para mantener el Estado, el Príncipe: "se ve obligado a actuar contra la fe, la humanidad, la caridad y la religión. Por eso, necesita un ánimo dispuesto a moverse según los vientos intempestivos de la Fortuna» (Maquiavelo, 2004: 133).
} 
materialista que despertó fuertes críticas entre sus contemporáneos. Ambos filósofos habrían logrado pensar la política desde sus relaciones de fuerzas efectivas y pasionales sin el recurso a las ilusiones trascendentes de la imaginación. Cuando no media un proceso de crítica, estas ilusiones promueven la sedimentación de algunos saberes y prácticas. Surgen así actitudes reaccionarias que obturan la apertura hacia el movimiento efectivo de lo real. El problema es que ambos pensadores quedaron sepultados por el peso del racionalismo moderno hegemónico que hereda el método de la tradición medieval. ${ }^{3}$ Sin embargo, hacia finales del siglo XX se produce un modo de abordar lo filosófico y lo político que encuentra en Maquiavelo y Spinoza sus antecesores más prolíficos.

Claude Lefort por ejemplo, sostiene que Maquiavelo le habla a la juventud incitándola a desafiar los ideales anquilosados del conservadurismo de su tiempo. En este sentido, recupera una interpretación abierta por Antonio Gramsci cuando sugiere que el realismo de Maquiavelo se relaciona con la impronta revolucionaria de Marx. ${ }^{4}$ La esencia de este realismo consiste en estudiar el mecanismo de la vida social con el fin de ponerlo en provecho de cada grupo que esté dispuesto a defender su posición. (Lefort, 1988: 150). Si Maquiavelo habla a los príncipes, no lo hace para darle consejos, sino para hacerlos conscientes de que el poder que ellos tienen es el resultado de una lucha social inscripta en una singularidad histórica. Ellos pueden ser víctimas de esas creencias ilusorias en las que su poder

3 El principio de personalidad de la Edad Media es el que impera en la racionalidad cartesiana que efectúa dos movimientos íntimamente conectados. Por un lado, reconocer en el "yo" una certeza indubitable. Por otro lado, recurrir a un presupuesto de la idea de Dios para garantizar el acceso de ese "yo" al mundo exterior.

4 En relación a este punto, Lefort afirma: "Esta cuestión está sin duda en los origines de la interpretación tan sugestiva que Antonio Gramsci ha presentado en sus notas sobre Maquiavelo. Su mérito viene de que, situándose en los horizontes del marxismo, no procura de ninguna manera encerrar el pensamiento maquiaveliano en los límites de un marco social donde se agotaría su significación, sino que tiende más bien a enlazar las dos teorías como dos momentos constitutivos de una experiencia sociológica de la realidad.» (Lefort, 1988: 149). 
se relaciona con las masas, o bien, pueden usar esta dinámica a su favor, insertarse satisfactoriamente en el juego del poder y generar desplazamientos necesarios. Por eso señala que el príncipe puede tener una función revolucionaria en contra de los sectores conservadores y en favor de sectores populares cuya potencia se encuentra relegada ${ }^{5}$.

En una línea de continuidad, Althusser sostenía que la única tradición materialista hundía sus raíces en el método esbozado por Maquiavelo y Spinoza. Las características de dicho método consisten en pensar la materialidad de esas ideas ilusorias de sentido. En otros términos, ubicar con precisión su lugar adecuado y no permitir que su dominio se extralimite. El mundo es una totalidad, pero la misma no es totalizable por ningún principio a priori, sino vivida en su dispersión, es decir, percibida como lo dado a lo que somos arrojados y a partir de lo cual forjamos nuestras ilusiones. El materialismo, decía el francés, es como subirse a un tren en movimiento y disfrutar del viaje sabiendo que no existe un origen prístino ni una finalidad última:

El materialista, por el contrario (del idealista), es un hombre que toma el tren en marcha (el curso del mundo, el curso de la historia, el curso de su vida) pero sin saber de dónde viene el tren ni hacia dónde va. Sube en un tren de azar, de encuentro, y descubre en él las instalaciones factuales del vagón y los compañeros de los que factualmente está rodeado, cuáles son las conversaciones y las ideas de esos compañeros y qué lenguaje marcado por su medio. (Althusser, 1985, p. 140).

Continuando esta impronta, Miguel Abensour se concentra en las implicancias que la filosofía de Maquiavelo y Spinoza tienen en Marx. El autor utiliza este vínculo para sugerir una operación de apertura del determinismo economicista propio del

5 En este sentido, Lefort afirma: El príncipe tiene una función revolucionaria por su sola función. Llama a los hombres que, mistificados, no tienen interés por la mistificación. No puede así sino vincularse a la empresa histórica de una clase que, para estar absorta en el presente en el irrealismo, no está menos Ilamada a convertirse al realismo absoluto. (Lefort, 1988: 150). 
marxismo más dogmático. Marx no habría rechazado el Estado en su totalidad, sino que habría abogado por un Estado racional y no teológico que concuerde con la naturaleza democrática de los hombres ${ }^{6}$. Contra las creencias de un marxismo más esencialista que realza el rechazo de Marx hacia las dinámicas institucionales vigentes, el autor concluirá que no importa tanto la forma institucional que se adopte mientras dicha forma no esté condicionada por presupuestos idealistas que se traduzcan a la práctica. (Abensour, 1998: 130).

Y más recientemente, Frederic Lordon (2015) se concentra específicamente en la filosofía de Spinoza, pertrechando la crítica marxista al capitalismo al revelar su anclaje en una servidumbre pasional. El autor sostiene que es necesario reemplazar la idea de una servidumbre voluntaria para explicar la potencia dominante del capitalismo actual. La sumisión de las personas a la dinámica de un totalitarismo financiero se encuentra en la captación del deseo de autoconservación, generando un acoplamiento de los deseos individuales a las tendencias impuestas por la economía hegemónica. La relación salarial es aceptada por el temor a perder los medios para satisfacer el deseo primigenio de subsistencia material. De este modo, quedan sometidas las voluntades disidentes y los afectos alegres quedan alineados a los vectores dominantes impuestos por el capitalismo financiero.

A partir de lo anterior, se aprecia que el vínculo entre Spinoza y Maquiavelo es recuperado para pensar el complejo nudo que se produce entre lo político, lo económico y los afectos subjetivos. El presente trabajo pretende insertarse en la senda abierta por estos debates. Mi objetivo es concentrarme específicamente en el método spinoziano para mostrar desde allí una concepción del derecho capaz de habilitar múltiples formas de

\footnotetext{
6 Afirma Abensour: «Vemos pues dibujarse con nitidez una línea de continuidad que va de Maquiavelo a Marx pasando por Spinoza, y que consiste en liberar la comunidad política del despotismo teológico a fin de devolver a lo político su consistencia propia y permitir así el advenimiento de un Estado racional» (Abensour, 1998: 36).
} 
ser, de sentir y de pensar. Siguiendo esta línea, resultará posible sugerir una torsión materialista de las prácticas jurídicas capaz de devolverle al dispositivo su dimensión real. La hipótesis radica en mostrar que a través de este método resultará posible evaluar el juego de determinaciones complejas y múltiples que subyacen a nuestras prácticas jurídicas. Estas no se reducen a una naturaleza esencialista del contenido del derecho que pasaría por alto la reificación y el carácter histórico e ideológico de las identidades y los códigos. Tampoco se reducen a la positividad de un código desde el cual solo habría que efectuar deducciones precisas para llegar hasta la sentencia "correcta". Por el contrario, tanto los códigos, como las decisiones jurídicas (jurisprudencia), son el efecto de un complejo entrelazamiento que se produce entre los saberes, las relaciones de fuerzas y los afectos subjetivos, cuya singularidad debe ser apreciada en cada caso.

\section{Materialismo de Spinoza}

\section{III.I. Reformulación del principio de Razón Suficiente}

Para lograr estos objetivos comenzaré haciendo un recorrido por algunos tópicos centrales de la ontología spinoziana entendiendo que permite vincularse de otra manera con los entes ideales. Luego, intentaré delinear de qué modo su método constituye una clave para evitar algunos excesos propios de la institución del derecho. Posteriormente, pondré de manifiesto de qué forma creo que su filosofía puede contribuir a pensar una acción jurídica que evite esos desaciertos.

Ahora bien, tal como fue mencionado anteriormente, creo que la apuesta fundamental del materialismo de Spimoza radica en desactivar los efectos de una racionalidad basada en ideas imaginarias de causalidad y finalidad para explicar el devenir de los acontecimientos. Ya en el Apéndice del libro Primero de la Ética sostiene que este prejuicio de raíz teológica (y teleológica) constituye el origen de los errores que produce la imaginación: 
Todos los prejuicios que me propongo indicar aquí dependen de uno solo, a saber, de que los hombres suponen comúnmente que todas las cosas naturales obran, como ellos mismos, por un fin y aun, sientan, por cierto, que Dios mismo dirige todas las cosas hacia un fin cierto, pues dicen que Dios ha hecho todas las cosas por el hombre y al hombre para que lo adore a él. (...) mostraré su falsedad y, finalmente, de qué manera de él han nacido los prejuicios del bien y el mal, del mérito y el pecado, de la alabanza y el vituperio, del orden y la confusión, de la belleza y la fealdad y otros de éste género. (Spinoza, 2014: 38).

Este punto es importante ya que vincula la función de la imaginación con los dilemas inherentes a todo ejercicio normativo que emite juicios para distinguir entre lo aceptable y lo condenable. Toda ley está vinculada estrechamente a una concepción de lo humano, a sus causas y fines, y por esa razón es importante pensar los supuestos filosóficos que intervienen en las distinciones señaladas. Es un hecho innegable que en toda sociedad existe un régimen que distingue lo normal de lo anómico. Es cierto también que genera algo de perplejidad advertir la inexistencia de un fundamento que, en sí mismo y con total legitimidad, permita fundar esa división. Es precisamente ante esta perplejidad que creo pertinente recuperar el método spinoziano en la convicción de que puede realizar una contribución importante para pensar estos temas.

En relación con esta problemática se han desarrollado algunos planteos contemporáneos entre los que se destacan, por su gran influencia, los estudios de Michel Foucault. El francés ha mostrado la contingencia de principios que se consideran naturales y necesarios. En efecto, se ha encargado de hacer explícita la historicidad de esos regímenes normativos y su vínculo con un estado de relaciones de poder. Y esto lo ha hecho tanto en lo que se refiere al contenido de los derechos como a sus aspectos procedimentales. Sus ideas han puesto en perspectiva histórica algunos objetos típicos de la acción legal como la locura y la delincuencia, mostrando su vínculo con 
un conjunto de relaciones sociales imperantes en una época específica. En un mismo movimiento mostró que el procesalismo jurídico de occidente no constituye el punto culminante de una racionalidad que se mueve hacia el progreso, sino que está ligado a determinadas relaciones políticas, ideológicas y religiosas que se consolidan en la Europa medieval y cristiana. $^{7}$ Claramente, Foucault se inserta en una línea de pensadores que ha procurado mostrar los anudamientos entre las instituciones y las pasiones de dominio. No obstante, su filosofía ha sido mal entendida y se ha pensado que la descripción de los regímenes de normatividad da lugar a un relativismo inoperante. Francois Ost, por ejemplo, sostiene que los análisis de Foucault son "simplistas y tramposos" (Ost, 2017: 46) y corren el riesgo de afirmar de un modo claramente ilegítimo que la institución del derecho se reduce a sus efectos de dominación.

Disidiendo de posturas como la de Ost, creo que el planteo de Foucault tiene el mérito de promover una mirada cautelar. En efecto, en relación con las finalidades y principios ilusorios aparece uno de los peligros más delicados de la institución del Derecho. Como señala el jurista argentino Raúl Zaffaroni, el derecho nunca puede ser un fin en sí mismo sino un instrumento para proteger la dignidad de la persona. Pero si la noción de persona pierde contacto con la realidad, el ejercicio del derecho se arriesga a convertirse en una mera ficción jurídica funcional a los intereses de los poderes de turno:

$\mathrm{Al}$ respecto es necesario advertir que la persona humana es un concepto jurídico pero necesitado de un dato real $\mathrm{u}$ óntico que es el ser humano. Cuando se lo pretende usar como concepto puro, desmaterializado, prescindiendo de ese dato, no se hace otra cosa que manipularlo para dejar abierto el camino a la ficción jurídica, que da lugar a que se considere que hay humanos no personas o más o menos personas." (Zaffaroni; Dias dos Santos, 2019: 64).

\footnotetext{
7 En este punto estoy siguiendo un trabajo de Juan Ortiz que se ocupa de estudiar en profundidad los aportes que tiene, para la teoría del derecho, la historia política de la verdad realizada por Michel Foucault. (Cf. Ortiz, 2019).
} 
Ahora bien, resulta sabido que para Descartes fue preciso hallar un método confiable para darse a la tarea del conocimiento y ese método encontraba en la idea de Dios su garantía absoluta. De manera contraria, para Spinoza, el método más apropiado para aproximarse a la verdad se despliega en la misma acción. El proceso de conocer se desarrolla a partir de la pluralidad de los efectos que constituyen la substancia:

Mas para mostrar ahora que la Naturaleza no se ha prefijado ningún fin y que las causas finales no son, todas, sino ficciones humanas, no es menester muchas palabras. (...) la doctrina del fin trastrueca la naturaleza. Pues lo que en realidad es causa, lo considera como efecto, y a la inversa. Además, lo que es por naturaleza anterior, lo hace posterior. Y, por último, lo que es supremo y perfectísimo lo vuelve imperfectísimo." (Spinoza, 2014 b: 40).

De este modo, Spinoza sugiere que no existe una norma preestablecida para el conocimiento del mundo, sino que es el proceso mismo del conocimiento el que constituye esa norma. En su Tratado sobre la reforma del entendimiento sugiere que no es la esencia inmaculada de la idea de un martillo la causa de todos los desarrollos tecnológicos producidos por la herramienta. Por el contrario, es el uso progresivo de operaciones rudimentarias las que derivaron en la forma de un martillo y en todo lo que éste pudo habilitar.

Así, la realidad pensada como una producción infinita de efectos conduce a considerar de otro modo el famoso principio de Razón Suficiente. La fórmula "Nada es sin causa" procedía de modo analítico desde los efectos (lo óntico, la indefinición del ser) hacia supuestas causas primeras que revestirían un carácter necesario. Las mismas se definían por atributos imaginarios (un Dios todopoderoso, omnipotente, que no puede engañarme) cuyo contenido se naturaliza y vuelve necesarios los fines contingentes creados por la imaginación de las personas. Así es como Descartes salía del encierro del "yo pienso". Encontraba una idea determinada y suponía que él no podría ser la causa de su contenido. 
En la filosofía de Spinoza se invierte este modo de razonar por otro que afirma "ninguna causa es sin producir efectos". La misma, procede de modo sintético desde el rastreo de causas reales, de potencias genéricas, a los efectos reales. ${ }^{8}$ Un ejemplo claro lo constituye la idea de Libertad. Como idea, es decir, como producto del pensamiento humano, no puede haber error en imaginar el concepto de Libertad. Tampoco puede haberlo si el objeto de la imaginación es un caballo con alas. Pero las personas se engañan si se creen libres de modo absoluto como suele sugerir ese concepto imaginario. Ya que su comportamiento se inserta en una red infinita de relaciones causales con otros procesos e individuos. En la proposición 48 de la segunda parte de la Ética, Spinoza afirma que: «En el alma no hay ninguna voluntad absoluta o libre, sino que el alma es determinada a querer esto o aquello por una causa que también es determinada por otra, y ésta a su vez por otra, y así hasta el infinito.» (Spinoza, 2014 b: 93).

Por ende, admitir esta multicausalidad en las decisiones del alma es un pensamiento más adecuado que suponerle una libertad absoluta. Esto no quita que haya un sentido de libertad sui generis en la filosofía spinoziana ligado al estudio del modo en el que estamos efectivamente sujetos a cierta relación necesaria con los demás. Lo cierto por ahora es que mediante este tipo de operaciones Spinoza desarma la jerarquía fundada por Descartes que erige al pensamiento como certeza indiscutible de acceso a la realidad ("pienso, luego existo"). Como bien advirtió Deleuze, el spinozismo es una filosofía rotundamente anti jerárquica que se abstiene de erigir una síntesis imaginaria como superior al ser efectivo de las cosas. ${ }^{9}$

8 En este punto sigo una reflexión de Pierre Macherey: «... el principio de causalidad tal como lo sugiere Spinoza, invierte literalmente los términos del principio tradicional: Ia tan conocida fórmula 'nada es sin causa', que procede de manera analítica del efecto a la causa, es sustituida por la nueva fórmula 'ninguna causa es sin producir efecto', que procede al contrario de la causa al efecto, sintéticamente, y que resume en una simple frase la concepción genética del conocimiento elaborada por Spinoza» (Macherey, 2013: 81-82).

9 Dice Deleuze en su curso sobre Spinoza: «Ven que Spinoza profundiza al máximo su oposición a toda una tradición filosófica, la tradición de lo Uno superior al ser. Lo que él va a 
Este es un punto crucial que distingue a Spinoza de Leibniz. Nadie niega la rigurosidad del pensador alemán. Pero es sabido que en su filosofía opera un presupuesto lógico y valorativo que se juzga como jerárquicamente superior al Ser de las cosas; El mundo actual es una elección Divina y ha sido creado eligiendo entre el mejor de los mundos posibles. El genio de Leibniz le permitió reconocer la posibilidad de infinitos mundos lógico - matemáticos. Le permitió asimismo advertir la importancia de las singularidades irreductibles en la constitución de estos mundos. Sin embargo, él subsumió estas intuiciones a un principio de necesidad con un contenido valorativo bien definido pero cuestionable. Aquello que sea la ley de lo mejor constituye un asunto sumamente discutible, pero actúa dándole un sentido a priori a una realidad que resulta, en principio, indeterminada. Esta falla es advertida por Spinoza cuando señala: «... nosotros queremos que todo esté dirigido de acuerdo con nuestra razón, y sin embargo, lo que la razón afirma que es malo sólo lo es con respecto a las leyes de nuestra naturaleza, pero no lo es si se consideran el orden y las leyes del universo" (Spinoza, 2014: 36). Comienza a percibirse aquí el punto de inflexión que puede introducir la filosofía de Spinoza. Que no consiste en negar la efectividad de algunas ideas, sino en reconocer la realidad de las mismas sin presuponerles un origen trascendente.

\section{III.II. Los riesgos del idealismo en la tipicidad jurídica}

De lo anterior se sigue que la filosofía spinoziana desactiva el supuesto de una finalidad ética trascendente. Siguiendo esta línea concibe el pensamiento y la extensión como atributos de una substancia infinita ${ }^{10}$, sin primacía de uno de ellos por sobre el otro. En ese movimiento, también se distancia de la

producir -creo que es una característica de Spinoza- es la filosofía mas antijerárquica que jamás se haya hecho.»(Deleuze, 2013: 44).

10 Quizá el término sustancia aquí puede desorientar un poco al promover la idea de un principio esencialista. No obstante, lo que Spinoza entiende por substancia se relaciona más bien con la idea de esa idea de totalidad no totalizable señalada más arriba. 
racionalidad dialéctica en la que aún parece subsistir un inmutable Principio de Personalidad. De acuerdo con Macherey la reflexión hegeliana es un pensamiento que se vuelve sobre sí como Sujeto. Spinoza y Hegel se acercan cuando ambos conciben al saber como un movimiento, proceso o despliegue y no como esencia. No obstante, se alejan sustancialmente en el momento en que es necesario desfetichizar el pensamiento mismo:

... también Spinoza se aleja de Hegel: al hacer del pensamiento un atributo de la substancia, constituye su movimiento como absolutamente objetivo y lo libera de toda referencia a un sujeto, incluso si este fuera el pensamiento mismo. A partir de allí, la causalidad esencial que está en la base de toda racionalidad se define sin presupuesto teleológico.» (Mecherey, 2013,p. 85).

Mientras que para Hegel el pensamiento llega a abarcar la totalidad de lo real, Spinoza lo presenta como un atributo más de lo real inserto en una trama innumerrable de otros atributos. Este punto es central, ya que no existe el Pensamiento, sino que existen pensamientos singulares, propios de cada sujeto, sociedad, cultura y pasibles de sufrir variaciones con los vaivenes de la historia.

Allí radica la torsión materialista spinoziana que promueve una descripción de las relaciones reales (deseos, afectos, ideas, movimientos, fuerzas), sin recurrir a un principio fundacional de carácter esencialista. Como señalé más arriba, Spinoza propone un modo de hacerse cargo de la realidad reconociendo su dispersión infinita no sometida a ningún poder de síntesis a priori. Las consecuencias de este tipo de inversión son grandes. Lo eran en el tiempo de Spinoza y lo son en el nuestro. Ya la crítica hegeliana advertía que Spinoza abogaba por una indefinición absoluta, razón que volvía a su filosofía bastante peligrosa. No tanto por malintencionada, ya que el movimiento inmanente de Spinoza resulta apreciado por el propio Hegel. Pero sí por defender una dispersión en la cual no resultaría posible reconocer ni definir lo singular, el sujeto, en suma, el 
concepto. El sistema de Spinoza dificultaría el paso del todo a la parte y esta indefinición se traduce en un inconveniente para establecer operaciones normativas. En primer lugar, la falta de fundamento para decir "esto". De allí deriva la imposibilidad de decir "esto es bueno o malo" que se traduce en una dificultad para deducir una legislación: "se debe esto y no se debe aquello".

El asunto es que hay un problema que ha llevado a la cultura humana a ejercer actos desastrosos de totalitarismo y autodestrucción. Y me atrevería a sostener que la causa de los mismos anida más bien en un problema de praxis filosófica que de tecnologías jurídicas o normativas. Si aquellas síntesis que fundamentan las operaciones normativas son ideales, ilusorias, o meras ficciones jurídicas en el sentido en que las hemos descripto, habrá muchos aspectos de la realidad que se juzguen como malos, inferiores, anormales, y, por ende, ilegales. Un ejemplo sugerente lo ofrece Diego Tatián cuando analiza la ligazón de gran parte de la filosofía Moderna con la legitimación del racismo. Incluso Hegel no ha sido inmune a este tipo de juicios: "Los africanos, dice Hegel, 'viven en la barbarie y el salvajismo' sin haber producido ninguna contribución civilizatoria; recluidos en sí mismos y por completo carentes de un reconocimiento universal, no constituyen un sujeto histórico» (Tatián, 2019: 86). Ante estas opiniones, Spinoza ya ofrecía un punto de disidencia entre las tendencias dominantes de la filosofía de su tiempo. En efecto, ya reconocía con agudeza que toda diferencia entre los hombres no debe imputarse como diferencias sustanciales impresas en la Naturaleza, sino que debe situarse en el complejo de relaciones que determinan las diferencias de poder y cultura: "La naturaleza es una y es la misma en todos. Sin embargo, nos dejamos engañar por el poder y la cultura.» (Spinoza, citado en Tatián, 2019: 91).

Creo que en este punto aparece la importancia de la filosofía de Spinoza para pensar algunos excesos. En efecto, existen una gran cantidad de problemas que surgen a causa de la incapacidad para establecer un vínculo adecuado con la idealidad de una tipología jurídica. Un tipo penal (supongamos, la figura 
del robo) es una creación de un poder estatal basada en una necesidad de ordenamiento normativo. Cuando una persona roba, se dice que su acción se adecúa a ese tipo previamente definido, su conducta es juzgada como típica, antijurídica y reprochable, y recibe por ello una condena. No obstante, cuando el tipo legal (que es una idealidad) se concibe como una realidad en sí misma (de manera similar al ejemplo de la libertad expresado mas arriba) y no como el resultado de un entramado de relaciones de poder y cultura (como señala el fragmento de Spinoza), las consecuencias de la acción jurídica pueden ser problemáticas ${ }^{11}$. Se pueden considerar a título de ejemplo los problemas que genera la tendencia a aplicar un Derecho Penal de Autor o enemigo. Esta es una figura muy criticada y nadie se atrevería a manifestarse a favor de ella en la actualidad. Se estudia en los manuales de derecho penal como el ejemplo supremo de lo que no hay que hacer. Suele leerse que el derecho en su evolución lleva a condenar sólo por actos determinados y nunca por la condición del autor. Sin embargo, se sabe que la selección que realizan los agentes de las fuerzas de seguridad está atravesada por sesgos basados en características de la persona independientemente del acto cometido. En su manual de Derecho Penal, los autores Zaffaroni, Alagia y Slokar sostienen que, si bien esta figura se aplica a casos muy puntuales como el régimen nazi en el que fue muy evidente, se aprecia también en la tendencia a la selectividad inevitable que genera la pulsión de policía en una sociedad: "Aunque resulte curioso,

11 En un famoso pasaje de Vigilar y Castigar, Michel Foucault constata esta variación de lo que podríamos Ilamar actualmente un tipo. El delito contra la propiedad no era la mayor preocupación para las instituciones que ejercían el poder político durante la Edad Media. Por el contrario, en el Antiguo Régimen, los delitos contra la propiedad, el hurto, algunos asesinatos, no recibían un castigo por parte del poder soberano o se encontraban regulados por resoluciones que, a causa de su inobservancia generalizada, perdían vigencia. Esta situación se revertirá con el cambio de las condiciones políticas y sociales: «El robo, tiende a convertirse en la primera de las grandes escapatorias de la legalidad en ese movimiento que hace pasar de una sociedad de la exacción jurídica y política a una sociedad de la apropiación de los medios y productos del trabajo, para decirlo de otra manera, la economía de los ilegalismos se ha reestructurado con el desarrollo de la sociedad capitalista» (Foucault, 2009:100). 
lo cierto es que el tipo es una formula textual de selección de acciones, pero que en la mayoría de los casos el poder punitivo usa para seleccionar, vigilar y molestar a personas por sus características, aunque nada tengan que ver con las acciones que esta fórmula criminaliza." (Zaffaroni, et al, 2007, p. 339)

En el ámbito de los estudios criminológicos es muy conocido que en Estados Unidos las estadísticas arrojan que siendo afroamericano o latino hay más probabilidades de ser arrestado, muerto por la policía o condenado a una sentencia más dura. ${ }^{12}$ Este tema se ha reavivado recientemente debido al asesinato del afroamericano George Floyd en Estados Unidos que tuvo un impacto grande en los medios a nivel internacional. El caso de Floyd grafica tristemente el modo en que opera la selectividad del aparato punitivo. Aún así, este punto es sumamente delicado. Porque en el discurso explícito nadie va a reconocer que está juzgando o actuando en base a características que no sean las del acto. En nuestro país, un ejemplo tristemente famoso ocurrió a fines del año 2017 en pleno gobierno neoliberal del expresidente Macri. El joven Rafael Nahuel participaba de un reclamo de tierras de la comunidad Mapuche en el sur de Argentina. Como consecuencia, fue reprimido por el poder policial y asesinado con balas de plomo estando totalmente desarmado.

Lo más preocupante en este tipo de casos es que, habitualmente, este juicio selectivo realizado en una primera instancia por el poder policial es refrendado por los Magistrados en el desarrollo de los juicios, incluso a través de las estrategias que

12 En un trabajo de reciente publicación, el sociológo francés Didier Fassin estudia detalladamente la selectividad del aparato punitivo en el ejercicio del poder de castigar tanto para el caso estadounidense como europeo. El trabajo aporta un conjunto muy nutrido de casos empíricos en los que se aprecia la selectividad inconsciente de la institución jurídica basada en características del autor y no del acto. Se inicia con el famoso caso del joven afroamericano Kalief Browder (Fassin, 2018, p.27) como ejemplo típico de la penalidad occidental para la cual el castigo es más importante que el propio crimen. Con el agravante que, en el caso puntual de Browder, el castigo se ejerce sin haberse confirmado nunca el supuesto hecho delictivo. Browder permanece en prisión preventiva durante años por negarse a auto culparse por un hurto. Una vez liberado, la situación traumática vivida lo conduce a quitarse la vida. 
habilitan las mismas tipicidades. Lo cierto es que en estas ocasiones pareciera que se produce a una reificación irracional del tipo, que pasa a defenderse como si fuera un mandamiento divino. La conducta juzgada como atípica resulta condenada independientemente de la intervención de otros factores (desigualdades estructurales en el acceso a otros derechos fundamentales: salud, educación, vivienda, alimentación, etc.). El sociólogo Didier Fassin en un estudio reciente sobre el castigo ofrece evidencias muy claras respecto del desconocimiento que los funcionarios judiciales tienen de estas cuestiones contextuales. Esa ceguera inconsciente se aprecia en las diferencias que el poder judicial realiza entre personas de diferentes sectores sociales y que se manifiestan sutilmente en las estrategias adoptadas en el manejo de los expedientes, de las audiencias, etc. ${ }^{13}$

Es posible afirmar que la necesidad de ordenamiento genera la tendencia dominante de las tipicidades. De allí se deriva la inevitable selectividad del poder punitivo a la que se refiere Zaffaroni. Por eso mismo es urgente considerar para el ámbito del derecho un modo diferente de vincularse con la idealidad de los tipos. Eso va de la mano de repensar algunos supuestos ontológicos que muchas veces siguen operando de modo acrítico en la praxis jurídica. En virtud de todo lo anterior, resulta interesante explorar la potencia que ofrece la filosofía de Spinoza para dotar de una dimensión más realista a nuestras instituciones jurídicas. Es decir, una dimensión que evite los

13 Es interesante el caso de un joven senegalés, sospechoso de un delito, es detenido por resistirse parcialmente a un control de identidad realizado en un barrio considerado peligroso por la policía. Por pertenecer a sector social desfavorecido, por no saber expresarse adecuadamente, manifiesta cierta insolencia en la audiencia con los jueces y se gana la enemistad de los mismo que lo dejan bajo custodia en prisión preventiva. Seguidamente, el tribunal pasa a analizar el caso de otro joven de un sector social mas acomodado, acusado de violar y violentar a su pareja. El joven se muestra, más solvente, se expresa mejor, lo acompaña un abogado remunerado y toda la actitud del tribunal cambia completamente: "Notable secuencia en el desarrollo de la cual el joven de origen senegalés acusado de haber respondido mal y resistido a los policías que, una vez más, lo controlaban y lo cacheaban sin motivo, va a prisión, mientras que el estudiante de buena familia, acusado de agresión física y sexual reiterada, reencuentra a sus padres y vuelve a casa." (Fassin, 2018, p. 178-179). 
excesos de una normatividad idealista y reconozca, habilite y proteja múltiples afirmaciones vitales. A la luz de lo visto, la pregunta que interpela es si el sistema de Spinoza permite operaciones de síntesis y qué tipo de función normativa es capaz de habilitar.

\section{El conatus: norma inmanente e impulso comunitario}

\section{IV.I. Principio normativo inmanente}

En virtud de lo anterior, creo que uno de los aportes fundamentales de la ontología de Spinoza para pensar estas cuestiones es su concepción inmanente de la verdad. El ejemplo del martillo esbozado más arriba conduce a pensar que la verdad es criterio de sí misma. Esto supone que no hay una relación temporal lineal entre una causa primigenia y sus efectos, sino que la realidad remite a una potencia infinita que produce infinitas cosas de infinitos modos (Tatián, 2012, p. 51). La idea de adequatio ya no se limita a evaluar la correspondencia entre un predicado y su objeto, sino que se orienta a percibir un método pertinente que permita pensar con rigurosidad esta potencia ontológica. Aquí se comprende la razón por la cual Spinoza recurrió a un método geométrico ${ }^{14}$. Lo que importa resaltar aquí es que en su filosofía no hay un principio esencial capaz de proveer una operación de cierre sobre la pluralidad o definir de modo absoluto una dirigencia normativa. El método inmanente conduce directamente a un enfoque relacional que, como fue sugerido en el apartado anterior, descree de la esencialidad de las tipicidades ideales y las analiza en relación una multiplicidad de factores.

Ahora bien, lo anterior no implica que el sistema de Spinoza proponga una realidad estática, sin movimientos y en la que todo está muerto. Muy al contrario, esa potencia ontológica mencionada permite el rastreo de una pluralidad de constantes

\footnotetext{
14 Ante la indefinición infinita de lo real la lógica axiomática permite inscribir rigurosamente un sentido allí dónde todo sentido imaginario es necesariamente finito y, por ende, mutable.
} 
genéricas que constituyen las diferentes potencias que tienen los modos finitos para actuar entre sí. El concepto de conatus es utilizado para representar los efectos de estas potencias. El mismo se define como el esfuerzo de cada cosa en perseverar en su ser. Lo verdaderamente singular de este esfuerzo es que no deriva de nada anterior ni más allá del devenir de las cosas mismas. Por esa razón, y casi como una anticipación a la idea lacaniana del deseo de deseo, el conatus es mero impulso deseante, es "deseo sin objeto" (Lordon, 2015: 35). Esta dinámica se percibe en el juego que se da entre las proposiciones VI y VII de la parte III de la Ética: "Proposición VI. Cada cosa se esfuerza, cuanto está en ella, por preservar en su ser; Proposición VII: El esfuerzo con que cada cosa se esfuerza en preservar en su ser no es nada aparte de la esencia actual de la cosa misma.» (Spinoza, 2014 b: 112).

El deseo así entendido (como movimiento efectivo sin finalidad última ni origen prístino) es la esencia misma de los hombres (Ética, III, Definición de los Afectos, I) y, por ende, ninguno de los institutos creados por el hombre puede tener otro origen. (Ética III, proposición IX, Escolio). En consecuencia, no hay artificialidad en el derecho, en la política, ni en las instituciones, sino que todas ellas son extensiones del deseo que tanto pueden potenciar afectos positivos como negativos. Así, al avanzar en la lectura es posible definir un criterio que permite efectuar una distinción entre afectos alegres y tristes de acuerdo con el modo en que potencian o reprimen las expresiones singulares del conatus:

Por alegría entenderé, pues, en lo que sigue, la pasión por la cual pasa el alma a una mayor perfección. Por tristeza, al contrario, la pasión por la cual pasa el alma a una menor perfección. (...) llamo afecto de la alegría, referido simultáneamente al alma y al cuerpo, placer y regocijo; al de la tristeza, por el contrario, dolor o melancolía. (Spinoza, 2014 b: 115).

Así, con esta tríada constituida por afectos alegres, afectos tristes y deseos, es posible definir un movimiento que tiende 
hacia una maximización de los afectos alegres. El impulso por conservar la vida expresa un movimiento, un afecto alegre expresado en el esfuerzo por aumentar el dominio y la intensidad de la potencia propia. En esta dinámica es posible encontrar el rastro de una norma. Lordon habla de una "normatividad inmanente de la potencia” (Lordon, 2018, p.190), como único principio normativo en la cantera spinoziana. Dicho principio jamás supone una síntesis anterior al devenir de los acontecimientos. Y nunca actúa como una finalidad absoluta más allá de las cosas mismas. Se sabe que los modos finitos de la substancia son contingentes y nunca pueden aspirar a la totalidad.

\section{IV.II. De la subjetividad a la transindividualidad}

Una vez delineada esta normatividad particular en la filosofía spinoziana es preciso despejar la segunda incógnita, es decir, aquella que se refiere a la definición de los modos singulares. El punto de vista del conatus supone que la realidad constituye una fuerza activa sin sujeto. No hay subjetividad deseante preexistente al impulso conativo. No obstante, esta ausencia no significa que sea imposible rastrear modos singulares finitos en los cuales se manifiesta la potencia del conatus. Una reflexión de Ethienne Balibar señala que la falta de un principio subjetivo no excluye el pensamiento de una individualidad abierta y relacional. En esta línea, propone una diferencia entre la intersubjetividad, deudora del planteo leibniziano que piensa al sujeto como mónada cerrada, y una transindividualidad pensada desde Spinoza. En efecto, el conatus se manifiesta a través de individuos ya que sólo las singularidades causales pueden actuar y producir efectos.

La clave está en pensar que el principio de personalidad no está dado de antemano, sino que se produce como un efecto de la potencia relacional de la substancia. Esta producción implica una conexión recíproca con otros modos individuales. Pero los mismos no constituyen interioridades cerradas sobre sí mismas, sino procesos abiertos de individuación recíprocos 
y simultáneos. En este sentido, Balibar sostiene: "Todo individuo llega a ser (y permanece, durante cierto tiempo) separado y único porque otros individuos llegan a ser (y permanecer) separados y únicos a su manera, en otras palabras, porque los procesos que llevan a separar las singularidades no están separados ellos mismos.» (Balibar, 2009: 18). Este punto es de gran importancia. La singularidad de cada individuo queda definida a través de la dinámica que lo hace distinto de otro, un giro que permite pensar el vínculo comunitario como una red infinita de modos singulares y afectos particulares. Este cambio de perspectiva conduce a valorar la irreductibilidad del individuo en simultaneidad con su necesaria relación con los otros. Así, se rompe con el binomio individuo - comunidad y con el juego que sugiere privilegiar a uno en desmedro del otro. La trama social recibe su impulso del conjunto de deseos singulares, pero sin recurrir a un supuesto esencial sobre el sujeto.

Esto se contrapone a la herencia liberal que nos ha dejado una metafísica del individuo como un "yo" cerrado sobre sí mismo. Ya Adam Smith creía que sólo al seguir ciegamente mi propio interés económico secundariamente seré beneficioso para el conjunto. Ello ha conducido a la ilusión de la libertad y la autosuficiencia del sujeto que sólo dependería de su iniciativa personal para subsistir. El problema es que esta idea ha derivado en un formalismo abstracto de la identidad y ha mostrado serias dificultades para reconocer que el sujeto es efecto de relaciones sociales e históricas. Lordon sostiene que incluso el punto culminante de la ilustración, expresado en el famoso "pensar por sí mismo" kantiano, supone un sujeto como mónada encerrada en su propia individualidad. Este dispositivo se ha acrecentado con el capitalismo neoliberal que desconoce relaciones políticas y funciona a partir del mito del mérito personal para lograr el éxito (Lordon, 2018, p 331).

El peligro de estos supuestos sobre la naturaleza del "Hombre" es que subyacen a las decisiones jurídicas. Es decir, promueven la creación de códigos y guían la interpretación de los mismos. En consecuencia, muchas veces operan legitimando 
principios de exclusión y discriminación bajo la apariencia de la libertad y el reconocimiento. Otras veces, actúan criminalizando y castigando ciertos comportamientos, y habilitando otros más funcionales a las formas de dominación vigentes. En otros términos, producen la famosa administración diferencial de los ilegalismos a la que se refería Michel Foucault. ${ }^{15}$ Por ejemplo, ¿por qué hurtar un chocolate de un kiosco está condenado por la ley y constituye un delito, pero la especulación y la acumulación indefinida del capital financiero y su efecto comprobado en la ruina sistemática de las economías mundiales, no está sujeta a ningún tipo de restricción?

Este razonamiento permite apreciar que, la práctica del especulador está apuntalada por ideas sobre la naturaleza del derecho, de la legalidad, de la libertad, del sujeto, del interés individual, y de la economía, que no resultan cuestionadas. El núcleo del problema es que la sedimentación histórica de este tipo de identidades no puede ser apreciada por la naturalización de los dispositivos. Este es otro de los problemas que anidan en los métodos idealistas y trascendentes. Se tornan incapaces de percibir que esa naturalización responde a relaciones de fuerzas cristalizadas que alimentan diversos regímenes de dominación. Hace un tiempo escuchaba un debate en Radio Mitre ${ }^{16}$ sobre la propuesta del economista francés Piketty de restringir mediante impuesto público el excesivo margen de ganancias de las grandes fortunas. Los periodistas argumentaban que la iniciativa sería precisamente una afrenta a los derechos de propiedad y a la

15 En su estudio acerca de la prisión, el filósofo francés afirmaba: «Sería preciso entonces suponer que la prisión, y de una manera general los castigos, no están destinados a suprimir las infracciones sino más bien a distinguirlas, distribuirlas, a utilizarlas; que tienden no tanto a volver dóciles a quienes están dispuestos a transgredir las leyes, sino a organizar la transgresión de las leyes en una táctica general de sometimientos. La penalidad sería entonces una manera de administrar los ilegalismos, de dar cierto campo de libertad a algunos y hacer presión sobre otros, de excluir una parte y hacer útil a otra. " (Foucault, 2008, 'p. 346).

16 Radio Mitre es una radio argentina perteneciente a la cadena de medios hegemónicos liderada por el famoso diario Clarín, de tendencia conservadora en lo político y marcadamente neoliberal en aspectos económicos como queda de manifiesto. 
prodigiosidad de supuestos genios como Bill Gates o Messi. El argumento era que ellos merecen todo lo que obtuvieron exclusivamente a causa de su carisma. La pregunta es, ¿hicieron Gates o Messi sus fortunas adentro de una burbuja y en una total soledad? ¿No resulta más racional y empático pensar que sus ganancias son el resultado de una gran composición y colaboración de flujos, afectos e intereses de otras millones de personas? ${ }^{17}$

\section{Spinoza y el Derecho}

En virtud de lo anterior, es manifiesto que la teoría del conatus produce una torsión materialista conducente a pensar de otro modo las exigencias normativas y la vida comunitaria. Tanto las ideas de Justicia como sus identidades correlativas aparecen como efectos de la potencia conativa. En este punto, es preciso aclarar que existe un vínculo entre los principios ideales de sentido (dimensión ontológica: por ejemplo, el principio de Persona) y lo real infinito (en sí mismo indiscernible: dimensión óntica). El mismo también tiene un asiento en el deseo. Ya que las creencias que tenemos sobre el mundo (en las que entran las ficciones que orientan nuestra vida institucional) constituyen un efecto de sentido necesario para desarrollar nuestras vidas. En consecuencia, es posible afirmar que las ideas también están

\footnotetext{
17 El reciente y polémico trabajo del economista Thomas Piketty titulado Capital e Ideología va en esta línea. Con un rigor histórico implacable el francés realiza un examen del origen de la desigualdad en las sociedades actuales como un resultado de la creencia en la defensa excesiva del derecho propiedad privada. La complejidad del asunto es que esa cuestión está profundamente anudada al modo en que cada sociedad justifica sus desigualdades: "La desigualdad no es económica o tecnológica: es ideológica y política. (...) Dicho de otro modo, el mercado y la competencia, los beneficios y los salarios, el capital y la deuda, los trabajadores cualificados y los no cualificados, los nacioonales y los extranjeros, los paraísos fiscales y la competitividad no existen como tales. Son construcciones sociales e históricas que dependen completamente del sistema legal, fiscal, educativo y político que decidimos establecer. "(Piketty, 2019, p.18). Por otra parte, en contradicción a la argumentación pobre de esos periodistas, el mismo Bill Gates declaró recientemente que su gran fortuna no tiene otro origen que las injusticias de la economía vigente. Que existen innumerables personas que trabajan igual de duro que él y viven miserablemente. Nota en: https://www.pagina12.com.ar/240517-billgates-a-favor-de-que-los-mas-ricos-paguen-mas-impuestos.
} 
ligadas a los afectos. Allí radica su poder para convencer sobre algunos aspectos, para generar alegrías o tristezas. En rigor, todo sentido de realidad es ficcional y cada uno de nosotros establece su propio vínculo con lo imaginario. No obstante, es preciso advertir ese juego para evitar su exceso imaginario, es decir, dar paso a la ilusión de que esas suturas ideales se sostienen en sí mismas, que pueden mantenerse fijas o que son válidas para todos por igual. Lo cierto es que el método spinoziano permite advertir los efectos de la ideología como un punto en el cual, por falta de crítica, los individuos reproducen creencias imsginarias sedimentadas.

En virtud de todo lo anterior, creo que las ideas de Spinoza permiten introducir dos operaciones novedosas en la trama de los estudios sobre Filosofía del Derecho. Operaciones capaces de establecer una sana sutura entre posturas aparentemente irreconciliables: por un lado, las teorías de la deconstruccción que han ejercido críticas necesarias, pero a veces paralizantes, ante los excesos del formalismo. Y por otro, aquellas posiciones que realzan de modo acrítico o fetichista la función normativa del derecho y las instituciones. Como analizaré a continuación creo que la reactivación de cantera spinoziana permite rescatar los efectos productivos del dispositivo como minimización de afectos tristes y estimulación de afectos alegres; al mismo tiempo, ofrece la ventaja de promover un uso de las instituciones que sea sensible ante la variedad del deseo, el movimiento de las disidencias y la afirmación de múltiples formas de ser.

\section{V.I. Spinoza corrige a Hobbes: Sostener siempre el derecho natural}

La clave para pensar lo anterior se retrotrae al punto en el cual Spinoza se distancia de Hobbes. En una de sus cartas a Jelles ante la pregunta de éste último por la diferencia entre el sistema de Hobbes y el suyo, Spinoza responde:

Me preguntáis cuál es la diferencia entre Hobbes y yo en cuanto a la política. Esta diferencia consiste en 
que yo sostengo siempre el Derecho Natural y en que no acuerdo derecho al soberano sobre los sujetos en cualquier ciudad en la medida en que, por la potencia, el soberano prevalece sobre ellos. (Citado en: Lordon, 2018: 203).

No hay dudas de que Hobbes da un paso significativo en la línea del realismo político. Advierte que las ideas de justicia y los valores morales no constituyen realidades esenciales y sólo es posible pensarlos a partir de la institución legal. Así, el inglés reconoce adecuadamente la diferencia entre aquello que pertenece al orden cultural de las creaciones imaginarias en contraposición a las relaciones de fuerzas reales. En estado de derecho natural, todo es posible y nada puede ser injusto, ilegal, o inmoral. Este es un punto de convergencia claro con la filosofía de Spinoza. En efecto, En su Tratado político, Spinoza afirma: "Del mismo modo que el pecado y la obediencia (en sentido estricto), tampoco la justicia y la injusticia pueden concebirse más que en un estado" (Spinoza, 2014: 41). Sin embargo, a mi criterio Hobbes sigue preso de una operación filosófica que consiste en oponer la razón a la pasión. Esta división se hace manifiesta en el final del famoso capitulo XIII del Leviatán. Allí sentencia que la salida del Estado de Naturaleza tiene su origen "en parte en las pasiones y en parte en la razón" (Hobbes, 2004: 132). Este supuesto lo conduce a pensar el Estado institucional como un "animal artificial" (Hobbes, 2004: 39) que se impone al régimen pasional de los individuos y las comunidades para implantar el orden. En estado de naturaleza, el hombre sería un lobo para el hombre, es decir, que la pasión predominante en el género humano es la agresión y que el deseo de sociedad sólo encuentra fundamento en buscar la paz por temor a la muerte.

Por el contrario, como fue sugerido más arriba, para Spinoza es el impulso del conatus el que apuntala a la institución jurídica. Esta norma inmanente no sugiere un sometimiento del deseo a la razón, sino una estimulación de afectos alegres. Es importante tener en cuenta que la razón también esta anudada con el deseo. En efecto, son las pasiones mismas las que 
pueden generar «un salto cualitativo a lo que Spinoza llama la vida de la razón" (Tatian, 2012: 112). En consecuencia, hay deseo de comunidad y en este deseo encuentra su origen la sociedad política y el entramado jurídico. Así, Spinoza opone al axioma hobbesiano del lobo, la certeza de que el bombre es un Dios para el hombre, que significa que la razón sugiere siempre la felicidad del otro como condición de mi propia felicidad. (Tatián, 2012: 55). En el Tratado Político queda de manifiesto que el derecho nunca reprime simplemente las pasiones, sino que las extiende hasta el punto en el cual, el derecho natural como ejercicio de las potencias de los conatus, sólo puede disfrutarse en la sociedad política:

Si dos personas se ponen de acuerdo y unen sus fuerzas, tendrán juntas más poder y por consiguiente, un derecho superior sobre la naturaleza que el que tiene cada una de ellas por separado; y cuanto más numerosos sean los hombres que pongan sus fuerzas en común, tanto mayor será el derecho de que dispongan (Spinoza, 2014: 38).

Así, el impulso de cada conatus singular motiva la constitución del Derecho Jurídico. Siguiendo esta lógica, es posible rastrear una convergencia de los individuos en las normas:

Como los hombres, según hemos dicho, se dejan guiar más por los afectos que por la razón, resulta que si los hombres quieren realmente concordar y poseer de algún modo un alma común, no lo harán mediante un precepto de la razón sino más bien en virtud de un sentimiento común como la esperanza, el temor, o el deseo de tomar venganza por algún daño sufrido. Como por otra parte todos los hombres temen a la soledad, porque ninguno de ellos tiene en la soledad fuerza para defenderse y procurarse las cosas necesarias a la vida, resulta que lo hombres tienen una apetencia natural por el estado civil y en consecuencia, nunca se puede hacer que ese estado quede disuelto del todo. (Spinoza, 2014: 59).

No hay duda de que esta coincidencia será siempre sinuosa, conflictiva, atravesada por la irreductibilidad de cada conatus 
singular, pero tiende hacia una demarcación más o menos general entre lo aprobado y lo desaprobado. Una polaridad que está a la base de la formalización jurídica entre lo legal y lo ilegal (Lordon, 2018: 232). Por ende, es la potencia y el afecto lo que permite comprender las imposiciones y el juego de sumisiones hacia un poder común. El giro generado por la filosofía spinoziana tiende a pensar que la institución extiende las pasiones y no únicamente aquellas destinadas a evitar la muerte. Así, para Hobbes, el Estado actúa poniendo un límite al deseo destructivo inherente a la naturaleza humana. En cambio, Spinoza sugiere que el derecho natural tiende a una potenciación de los afectos $\mathrm{y}$, por ende, se maximiza con la constitución del Estado. Desde este punto, la institución no es buena por ser una idea perfecta de convivencia sino por ser un efecto de la naturaleza deseante de la substancia. En resumidas cuentas, mientras en la perspectiva hobbesiana el derecho tiene un carácter prohibitivo, en la lógica spinoziana el derecho no se limita a evitar la muerte sino a cultivar la vida. Siguiendo esta línea, una reflexión de Diego Tatián muestra de manera convincente que para Spinoza la democracia constituye el más natural de los regímenes políticos:

El derecho natural es ínfimo en el estado natural, y máximo bajo la condición política-que no requiere la cancelación de la libertad ni neutraliza la potencia natural como sucedía en Hobbes, sino antes bien la extiende, la colectiviza, la incrementa, la enmienda, la desvía de su expresión inmediata para su elevación a una plenitud cuya radicalidad mayor será obtenida en el régimen democrático o popular. (Tatián, citado en Spinoza, 2014: 19).

\section{V.II. Ni crítica paralizante ni fetichismo jurídico}

Encarar la tarea judicial desde esta mirada promueve un uso del derecho que habilita y reconoce la pluralidad de los deseos singulares. Es preciso tener en cuenta que el individuo se dibuja relacionalmente en ese proceso que lo hace distinto de los demás. Esto permite evitar que una idea esencial de la 
Persona humana, cargada ideológicamente, resultado de una sedimentación histórica de creencias y saberes, se convierta en un principio inmutable para juzgar sobre una realidad cambiante que siempre excede la tipificación ideal. Inicialmente, todo armado normativo supone un límite para la expansión de cada deseo singular. Desde ese punto, la institución tiene un anclaje en afectos tristes. No obstante, los afectos alegres que produce la asociación logran someter su contraparte negativa dando primacía al deseo político. El problema se presenta cuando esta dinámica pasional contribuye a consolidar un régimen de dominación generalizado. Este es un exceso que se debe evitar. Como bien advierte Lordon en su libro Capitalismo, deseo y servidumbre (2015) el actual totalitarismo financiero se aprovecha de esta servidumbre pasional canalizando la fuerza de los deseos singulares en el beneficio para unos pocos.

Por esta razón, es preciso estudiar usos del dispositivo que permitan señalar los vínculos efectivos entre las pasiones, las relaciones de fuerzas, y los sistemas de dominación. Claramente, las ideas trabajadas permiten advertir el peligro que supone afirmar identidades e instituciones ideales sin reconocer relaciones de fuerzas efectivas. El sistema financiero actúa bajo el supuesto de la legalidad de todas sus operaciones aunque cause efectos atroces en las sociedades humanas; La dinámica de poder neoliberal encierra al individuo a través de una captura de sus deseos más genuinos. Pero posee un componente ideológico que convence a la mayoría de estar en la línea de la realización personal. En este sentido, el método spinoziano puede pensarse en sintonía con todas aquellas posturas que han denunciado el fetichismo de los dispositivos como factores de reproducción de los sistemas de dominación. Podrían citarse aquí los trabajos ya clásicos de Foucault, Deleuze, Agamben, y Espósito entre muchos otros.

Ahora bien, todo lo anterior permite introducir otra operación novedosa. En efecto, un método que reconoce la inmanencia realza, al mismo tiempo, la imposibilidad de operar por fuera del dispositivo. Un rechazo absoluto a la acción del 
mismo conduce a una perspectiva idealista del ímpetu revolucionario. Cabe preguntarse si allí no continuaría operando la lógica hobbesiana de pensar que la institución es un artificio trascendente que se impone sobre sujetos pasivos, anteriores, y preexistentes a la dinámica institucional. Esa vía de reflexión, si bien hace uso de la potencia de la crítica, genera un efecto de parálisis ante la pregunta por el sentido que deberíamos darle a una mutación global de nuestras formas de vida. En consecuencia, para generar transformaciones reales en las relaciones de fuerzas, parece más viable inmiscuirse entre las propias tramas del poder instituido -que ejerce coerción pero al mismo tiempo nos constituye y se anuda a nuestro deseo- para desplazar desde allí algunas cuestiones. Por esa razón, Althusser veía como un gesto supremo de materialismo la reflexión de Spinoza que no rechazó en su totalidad la idea de Dios. Sino que utilizó estratégicamente el peso de esa noción para desplazar algunos de los efectos negativos generados por el dogmatismo que produce la creencia en una deidad personal. ${ }^{18}$

En una línea similar, Zaffaroni rescata la militancia del jesuita y poeta Firedrich Spee en contra de los juicios emanados de la criminología hegemónica de su tiempo basada en el Malleus Maleficarum. Si bien Spee no salió a decir literalmente que las brujas no existían, sí afirmaba que él jamás había visto una. Cabe aclarar que era sacerdote confesor de las víctimas condenadas a muerte. Así, en un clima totalmente adverso y en una época poco propicia para enfrentar al poder político, Spee

\footnotetext{
18 Althusser señala: « Lo que me fascinaba también en Spinoza era su estrategia filosófica. Jacques Derrida ha hablado mucho de estrategia en filosofía y tiene razón, puesto que toda filosofía es un dispositivo de combate teórico que dispone las tesis como si fueran plazas fuertes o voladizos para poder, en sus alusiones y ataques estratégicos, cercar las plazas teóricas fortificadas y ocupadas por el adversario. ¡Pero Spinoza empezaba por Dios! Empezaba por Dios, y en el fondo (lo creo, como toda la tradición de sus peores enemigos) era ateo (como Da Costa y tantos otros Judíos portugueses de su tiempo). Suprema estrategia; empezaba por cercar la suprema plaza fuerte de su adversario, o aún mejor, se instalaba en ella como si él mismo fuera su propio adversario y así no sospechoso de ser un adversario declarado, y redisponía esa fortaleza teórica, dándole completamente la vuelta, del mismo modo que se da la vuelta a los cañones dirigiéndolos contra el ocupante.» (Althusser, 1985: 138).
} 
actuó de modo muy estratégico. Se esforzó en probar que las personas juzgadas eran inocentes y que el método de tortura, los jueces tendenciosos, la ausencia de abogados, la crueldad y corrupción de los verdugos, convertían a cualquier vecino en culpable de los crímenes más demoníacos. ${ }^{19}$ De este modo, su trabajo Cautio Criminalis es visto como una obra pionera de la criminología crítica además de considerarse una contribución efectiva en la desaparición de los juicios por torturas.

Así, el axioma spinoziano que piensa el derecho como una extensión de las pasiones permite realizar algunas distinciones importantes: Por un lado, rechazar el fetichismo de las instituciones y mostrarlas en la crudeza de sus relaciones reales. En ese movimiento se hace posible reconocer el punto en el cual el dispositivo puede cristalizarse en torno ideas imaginarias o síntesis ideales que impiden el efectivo reconocimiento de los derechos reales. Por otra parte, al reflexionar sobre el entramado entre el derecho y las pasiones, no genera un rechazo de los dispositivos sino que invita a pensar nuevos usos para las prácticas jurídicas. En suma, habilita una producción inmanente de Justicia que "no admite 'sacralización' ni fetichización" (Tatián, 2019: 136), sino que resulta sensible a la potencia de la multitud sin descuidar el movimiento de los deseos singulares.

\section{V.III. Hacia una filosofía inmanente del Derecho}

Creo que estas operaciones pueden tener consecuencias importantes para pensar el derecho. La torsión materialista que he señalado en el presente escrito conduce a pensar las instituciones como efectos de la potencia del conatus. En consecuencia, la síntesis que fundamenta la acción jurídica no es

\footnotetext{
19 En relación a este punto, Zaffaroni señala: «Desde 1631 nos llega por la pluma de Friedrich Spee esta fórmula. El jesuita poeta adoptaba esta táctica: no entraba en la discusión acerca de la existencia y poder de las brujas, sino que se limitaba a la verificación de que las quemadas no eran brujas, sino mujeres inocentes. Por eso aconsejaba prudencia, cautio criminalis, manejar el aparato con cautela. De haber optado por el otro camino, se hubiese perdido en especulaciones pseudoteológicas con los teóricos que reforzaban la causalidad mágica de la criminología mediática de su tiempo" (Zaffaroni, 2018, p. 492).
} 
trascendente con respecto al desarrollo de los acontecimientos. Por el contrario, se presenta como un efecto de las potencias singulares que deriva en la conformación de un criterio general (aunque no necesario ni transhistórico) para realizar la distinción legal. Pero la operación innovadora derivada del planteo spinoziano es que la ley no actuaría como una ficción que busca imprimirse en los hechos y que, presa en su idealismo, condena a una realidad que no se ajusta a ese ideal; sino que toma como punto de partida el movimiento efectivo de lo real y por ende la singularidad de cada sujeto -ya sea individual o colectivo-, de sus deseos, de sus vínculos afectivos, de su historia de vida. Así, queda establecido un uso del dispositivo jurídico capaz de habilitar pliegues en las estructuras normalizadas de la sociedad, pliegues caracterizados como afirmaciones vitales y singulares que reivindican, por sobre todas las cosas, el derecho a tener derechos. ${ }^{20}$

Este uso del derecho estimula una convergencia saludable entre la potencia de la multitud y el reconocimiento de la potencia de actuar de cada individuo. No hace falta rechazar el dispositivo jurídico en su totalidad cayendo en un exceso anárquico e idealista. Eso esquivaría la espinosa cuestión del sentido que deberíamos otorgarle a la organización social, y la pregunta sumamente paradójica de quién o quiénes tendrían el poder para alumbrar el acceso al futuro. Más prudente resulta trabajar para mostrar los excesos de las prácticas y señalar desde allí algunas vías de transformación posible. La norma inmanente

20 En esta línea, me parece interesante una reflexión de Roque Farrán que recupera este gesto arendtiano poniendo el énfasis en la potencia ontológico- política del derecho y realzando la apertura constitutiva de su contenido: "Del mismo modo que la inmanencia es 'inmanencia de inmanencia' y no inmanencia de 'algo' o de 'alguien' (Deleuze), y el deseo es 'deseo de deseo' (Lacan), el derecho a tener derechos desindividualiza el sentido posesivo de la ley al tiempo que lo destotaliza, en el sentido de que no hay un metalenguaje que codifique burocráticamente todos los derechos particulares (no hay conjunto de todos los derechos). Se abre así el lugar irreductible de una singularidad genérica. Pues la ley, reconducida a las figuras imaginarias de la individualización-totalización, resulta omnipotente y desastrosa. Solo abierta a la indeterminación de lo real (...) es posible darle un sentido genérico que continúa indagando en su apertura constitutiva» (Farrán, 2016: 95). 
que se deriva del planteo spinoziano funciona como una especie de bilo de Ariadna para orientar esta tarea sinuosa y cargada de perplejidad. Existen ejemplos de legislación reciente que podrían apreciarse como usos del derecho que merecen potenciarse.

La legalización del matrimonio igualitario en Argentina, que se produjo en el año 2010; la lucha por ampliar el reconocimiento de diversas identidades de género, que adquirió carácter de ley en el año 2012; la importancia que han adquirido los debates actuales por la legalización del aborto, encabezados por grupos de mujeres que esgrimen críticas profundas a la ideología del patriarcado. Y creo que también podría citarse el caso de la nueva Ley de Salud Mental en Argentina, la ley 26.657 sancionada en el año 2010, que ha sido menos conocida que las anteriores pero que esgrimió un claro contrapunto contra el modelo positivista y biológico imperante anteriormente. La misma se propuso introducir una modificación en el sistema jurídico que sea capaz de valorar la condición humana integral de la persona con determinados padecimientos. En este sentido, se procedió al reemplazo de la carátula "Insania y Curatela» que rotulaba de modo definitivo a un individuo como "insano", "incapaz", circunscribiendo la intervención de la justicia únicamente a establecer la "Determinación de su Capacidad Jurídica». ${ }^{21}$

21 En el mencionado trabajo sobre Foucault y el Derecho el autor Juan Ortiz estudia con más detalle los puntos innovadores de la Ley de Salud Mental (26657) con respecto al paradigma legal anterior: "Esto supone un dictamen abierto que sólo tiene validez por tres años (art. 42), un plazo a partir del cual puede hacerse una reconsideración. El espíritu de la ley propone considerar múltiples estrategias para facilitar la vida de la persona con padecimientos a través de una valoración de sus vínculos afectivos, sociales, familiares y considerando la internación solamente en casos extremos y por un período que sea lo más breve posible (art.15). Es destacable también que la ley reemplazó la famosa pericia psiquiátrica -objeto de la crítica foucaulteana-, destinada a detectar la peligrosidad futura de un individuo, por una evaluación interdisciplinaria en la que intervienen tres profesionales de diversas ramas del conocimiento: Un perito psiquiatra, un perito psicólogo, un perito asistente social. En ella a su vez participan un juez de familia, un asesor jurídico del Estado, un familiar o persona responsable. Esto supone un reconocimiento de la sobredeterminación compleja que subyace a la emisión de un dictamen sobre la salud mental, es decir, procede a una valoración de la multiplicidad de factores que pueden incidir en los padecimientos de la vida de una persona. 
Éstos son sólo algunos ejemplos de un modo de pensar el derecho orientado a potenciar afectos alegres y a disminuir afectos tristes basados en supuestos ideales (la esencialidad del género o de la distinción sano e insano) como la discriminación y la exclusión del campo de lo normalizado. Se aprecia allí un uso de la potencia colectiva de la institución jurídica para habilitar el reconocimiento y la defensa de modos de existencia singulares en vistas de que cada persona pueda contribuir, desde su lugar irreductible, a enriquecer la vida del conjunto.

No obstante, tal como he mencionado en algunos puntos de este trabajo, gran parte de la institución del derecho sigue enfocada en la estimulación de afectos tristes. Zaffaroni y Dias dos Santos advierten las paradojas que entrañan para el derecho el totalitarismo financiero imperante cuyo funcionamiento supone una violación sistemática de todos los tipos penales. Es decir, su desarrollo tiende a borrar los límites entre la ilegalidad y las prácticas económicas hasta el punto de configurar una especie de macrocriminalidad financiera. Basta con agarrar cualquier código penal para advertir que los comportamientos de la economía financiera podrían encuadrarse dentro de los tipos penales más conocidos de acuerdo a bienes jurídicos que resultan macrolesionados: la vida y el futuro de las personas, de las comunidades, del ambiente. Así, los tipos de la extorsión, coacción, usura, estafa, administración fraudulenta, cohecho, reducción a servidumbre, encubrimiento por receptación, podrían imputarse a las agencias y los gobiernos que utilizan los medios que ofrece una economía de la ganancia financiera en conjunción al endeudamiento externo. La extorsión, la coacción, la colonización de la vida actual y futura se perciben en la instigación de los Organismos de Crédito que conducen directa o indirectamente a países emergentes a condiciones usurarias de negociación. Las mismas derivan en el ajuste operado en

\footnotetext{
Éstos no se limitan a cuestiones de orden biológico o legal, sino también a aspectos sociales, históricos, culturales, psicológicos, afectivos, tal como lo menciona al art. $3^{0}$ de ese cuerpo legal." (Ortiz, 2019, p. 241).
} 
sectores públicos con el riesgo que eso supone para los derechos humanos. Por todo esto, ni siquiera es necesario salirse de las propias tramas del derecho positivo para percibir que algo falla:

Cuando un Estado contrae deuda por porcentajes peligrosos en relación con su PBI, los intereses se vuelven leoninos. Si el administrador de los bienes de un incapaz contratase créditos leoninos, además de anularse los contratos por usurarios, sería condenado por administración fraudulenta, conforme al tipo penal Untreue o Infidelidad de los alemanes, pero nada de eso suele suceder cuando se administra un Estado y los bienes de millones de habitantes, incluso cuando se contratan excediendo poderes constitucionales (incluso por dictaduras o regímenes de facto) en connivencia con autócratas corporativos, lo que, además, hace sospechar macrohechos. (Zaffaroni; Dos Santos, 2019: 101-102).

A la luz de los hechos, parece ser que tenía razón Foucault cuando aseguraba que incluso para las prohibiciones hemos sido totalmente aburridos, sumisos y poco inventivos. ${ }^{22} \mathrm{Se}$ siguen dictando sentencias arbitrarias y desproporcionadas para delitos menores. Un ejemplo claro lo constituye el uso indiscriminado de la prisión para el tratamiento de los mismos. Se sabe que la prisión reproduce la delincuencia, destruye la existencia personal del condenado y por ende afecta negativamente a la vida del conjunto. Aún así, hay sentencias que condenan a un año y medio de prisión una tentativa de hurto. ${ }^{23}$

22 “Lo que me está prohibido ha sido siempre la misma cosa. Y somos sociedades que han inventado muy poco en el orden de la prohibición, inventando tan poco, tanto en la dimensión de la prohibición como en la del deseo. En la dimensión de la prohibición de los placeres también se ha inventado muy poca cosa. Lo prohibido es siempre lo mismo." (Foucault, 2018: 201). 23 Así ha decidido por ejemplo la Cámara Nacional de Casación en un fallo de Febrero de 2019: “....l. Que en lo que aquí puntualmente interesa, el 26 de junio de 2017, el Tribunal Oral en lo Criminal nro. 5 de esta ciudad, dictó sentencia y resolvió: "I. CONDENAR a E., [...] como autor del delito de hurto en grado de tentativa, a la pena de 3 meses de prisión y costas (artículos 29 inciso 3, 42 y 162 del C.P y 530 y 531 del C.P.P.N); II. Condenar a E., en definitiva, a la PENA ÚNICA de 1 año y 3 meses de prisión, debiendo regirse las costas por sus respectivos pronunciamientos..." (...) "En virtud del acuerdo que antecede, la Sala 
Como contrapartida, el sistema judicial es incapaz de cuestionar la legalidad ni mucho menos accionar en contra de las bases de un conjunto de prácticas financieras que producen sistemáticamente pobreza, desigualdad, violencia y exclusión.

\section{Comentarios finales}

Lo anterior demuestra que la tarea no es sencilla. Existe una fuerte sedimentación de saberes, prácticas, relaciones de poder que actúan generando coágulos en el desarrollo de las relaciones sociales. El asunto es que resulta sumamente complejo poder desanudar este tipo de coágulos ya que atañen a las convicciones, creencias e intereses particulares de magistrados, funcionarios, empresarios de medios de comunicación y de la población en general. En estos casos, la irreductibilidad de los modos singulares resulta contraproducente. Ya que muchas veces (la mayoría, lamentablemente) esas creencias con sus prácticas correlativas se despliegan sin mediar una reflexión profunda. Se aprecia así, que la materialidad en juego en todo lo que se ha trabajado se produce en el vínculo complejo que se establece entre una forma de saber normalizado, un conjunto de relaciones políticas y las identidades a las que adscriben los propios sujetos. Por esta razón, es tan difícil habilitar los juicios discrecionales en la praxis del derecho. Es decir, privilegiar los criterios en cada caso singular y no limitar el juego a la aplicación mecánica del código puro y duro. Muchas veces, los jueces se abstienen de sentenciar con criterios distintos a la racionalidad hegemónica por el temor al costo político que pueda ocasionar. Los mismos, impulsados por una criminología ingenua y una

II de la Cámara Nacional de Casación en lo Criminal y Correccional de esta ciudad, por unanimidad, RESUELVE: RECHAZAR en su totalidad el recurso de casación interpuesto por la defensa de Ever Flavio Santamaría Pulido y, en consecuencia, CONFIRMAR la sentencia aquí impugnada en todo cuanto fue materia de agravio; con costas, atento el resultado de la presente (arts. 456 , incs. $1^{\circ}$ y $2^{\circ}, 463,465,468,469,470$ y 471 a contrario sensu, 530 y 531 , CPPN). Regístrese, notifíquese, oportunamente comuníquese (Acordada 15/13 C.S.J.N. y LEX 100) y remítase al tribunal de procedencia, sirviendo la presente de atenta nota de envío." (http://www.pensamientopenal.com.ar/system/files/2019/04/fallos47585.pdf) 
escasa ética profesional, recomiendan penas más duras y escasa tolerancia hacia acciones delictivas menores, condicionando de este modo a tomar acciones que muchas veces vulneran los criterios más racionales del debido proceso. Cabe aclarar que estos juicios mediáticos pivotean sobre supuestos ideológicos sedimentados en la opinión pública. En consecuencia, es urgente que el derecho, tanto en el plano de su fundamentación teórica como en sus trayectos formativos y en la aplicación cotidiana de la norma, reconozca y trabaje sobre esos vínculos que he rastreado entre lo imaginario, lo político y lo afectivo.

Allí se pone en juego la materialidad misma de los dispositivos. Y creo que la filosofía de Spinoza permite reflexionar sobre la dimensión genérica de los mismos. Para decirlo de manera concreta, es deseable que las prácticas jurídicas sean capaces de reconocer la diversidad de esos anudamientos sin aferrarse a una sutura ideal e imponiéndola como contenido universal y necesario. También es deseable, y esto es lo más importante, que el derecho ejerza su acción evitando esos coágulos que inmovilizan el juego de relaciones entre esos términos. Esto permitirá el reconocimiento de aquellas luchas singulares que buscan tanto la ampliación de los derechos, como la invención y la afirmación de diversas formas de vivir. En este punto, no hay que dejarse engañar por la propaganda de la ideología neoliberal que promueve una libertad y una diversidad sólo superficial pero que no está dispuesta a cuestionar las identidades naturalizadas que le dan sustento.

Así, lejos de generar un rechazo absoluto de las instituciones, estas reflexiones son capaces de darle al derecho su lugar preciso en el desarrollo las relaciones sociales. La función normalizadora no es necesariamente una sutura dominante. Por el contrario, está basada en el movimiento de afectos alegres, razón por la cual, no es negativa cuando se realiza a través del reconocimiento de la compleja dinámica de los deseos singulares y colectivos y ejerce una acción orientada a habilitar, reconocer y articular del mejor modo posible, esos pliegues irreductibles que constituyen los fenómenos de disidencia. En este sentido 
creo que el argumento que he expuesto en el presente trabajo puede contribuir a promover un ejercicio del derecho que no se piensa desde un lugar más fundamental (ya sea ideal o trascendente) o desde la defensa de algún principio de superioridad biológica, étnica, racial, nacional, racional, o económica. Por el contrario, se define en una relación de inmanencia respecto a los procesos sociales y sin una postulación idealista en relación a su contenido.

\section{Bibliografía}

Althusser, Louis (1985) "La única tradición materialista" en Youkali. Revista de las artes y al pensamiento. En línea en: www. youkali.net

Balibar, Etienne (2009) "De la individualidad a la transindividualidad" Grupo Editor Encuentro. Córdoba

Abensour, Miguel (1998) La democracia contra el estado. Editorial Colihue. Buenos Aires.

Deleuze, Gilles (2013) En medio de Spinoza. Editorial Cactus. Buenos Aires.

Farrán, Roque (2016) Nodal. Método, Estado, Sujeto. Editorial La Cebra. Buenos Aires.

Foucault, Michel (2008) La Verdad y las Formas Jurídicas. Editorial Gedisa. Buenos Aires

- (2009) Vigilar y Castigar. Nacimiento de la prisión. Editorial Siglo XXI. Buenos Aires

- (2018) ¿Qué es la Crítica? Editorial Siglo XXI. Buenos Aires

Hobbes, Thomas (2003). Leviatán. Editorial Losada. Buenos Aires

Lefort, Claude (1988) Las formas de la historia. Ensayos de antropología política. Editorial Fondo de Cultura Económica. CDMX Lordon, Fréderic (2015) Capitalismo, deseo y servidumbre, Marx y Spinoza.Editorial Tinta Limón. Buenos Aires.

- (2018) La sociedad de los afectos. Por un estructuralismo de las pasiones. Adriana Hidalgo editora. Buenos Aires.

Macherey, Pierre (2013) Hegel y Spinoza. Editorial Tinta Limón. Buenos Aires. 
Maquiavelo, Nicolás (2004) El príncipe. Editorial Losada. Buenos Aires.

Ortiz, Juan (2019) "Michel Foucault y los aportes de una historia política de la verdad a la Teoría del Derecho" en Revista de Derecho Penal y Criminología. № 05, Año 9. Editorial La Ley - Thomson Reuters. Buenos Aires

Ost, François. (2017) “¿Para qué sirve el derecho? Para contar hasta tres" en Doxa. Cuadernos de filosofía del derecho, $\mathrm{N}^{\circ} 40$. Universidad de Alicante. España. En línea en: https://doi. org/10.14198/DOXA2017.40.01

Piketty, Thomas (2019) Capital e Ideología. Editorial Paidós. Buenos Aires.

Spinoza, Baruch (2014a). Tratado Político. Editorial Quadrata. Buenos Aires.

- (2014b). Ética demostrada según el orden geométrico. Editorial Gredos, Barcelona.

- (1988) Tratado de la reforma del entendimiento. Principios de filosofía de Descartes. Pensamientos metafísicos. Editorial Alianza. Madrid.

Tatián, Diego (2012) Spinoza. Una introducción. Editorial Tinta Limón. Buenos Aires.

- (2019) Spinoza Disidente. . Editorial Quadrata. Buenos Aires.

Zaffaroni, Eugenio Raúl (2018) La palabra de los muertos. Conferencias de Criminología cautelar. Editorial El Siglo. Quito

Zaffaroni, Eugenio Raúl.; Dias dos Santos, Ilison (2019) La nueva criminología crítica criminología en tiempos de totalitarismo financiero. Editorial El Siglo. Quito

Zaffaroni, Eugenio Raúl, Alagia, Alejandro. Slokar, Alejandro. (2007) Manual de Derecho Penal. Editorial Ediar. Buenos Aires. 